\title{
Prevalence of Musculoskeletal Disorders among Dentists in Al-Madinah, Kingdom of Saudi Arabia
}

${ }^{1}$ Talat H Al-Gunaid, ${ }^{2}$ Rayan Abdulhai, ${ }^{3}$ Baha Flemban

\begin{abstract}
Introduction: Musculoskeletal disorders (MSDs) are one of the most common occupational hazards associated with a wide range of occupations. Dental professionals have an increased risk of developing such disorders caused by repetitive, hard, or stressful gestures. Taking this issue into consideration, we felt the necessity to investigate the prevalence and distribution of musculoskeletal symptoms among dentists in Al-Madinah
\end{abstract}

Materials and methods: A self-reported questionnaire was distributed to a random sample of 180 dentists from different parts of Al-Madinah, Kingdom of Saudi Arabia. The questionnaire was about musculoskeletal symptoms in different parts of the body.

Results: A total of 70 questionnaires were completed and returned. Of the respondents, 47 (67.1\%) were males and 23 $(32.9 \%)$ were females. The mean age of respondents was $36.1 \pm 8.7$. Majority were general dental practitioners [45 $(64.2 \%)]$, with the remainder being specialists [25 (35.8\%)]. Prevalence of MSD during the past 12 months was reported to be lower back pain $(65.7 \%)$, neck pain $(48.6 \%)$, and shoulder pain $(45.7 \%)$, with the lowest prevalence pain being found in the hips and thighs (17.1\%).

Conclusion: The results suggested that the prevalence of musculoskeletal symptoms among dentists in Al-Madinah, Kingdom of Saudi Arabia, is high. Continuing education for dentists and dental students about the proper and correct dental positions as well as practicing ergonomic skills and incorporating them into the curriculum would be beneficial.

Keywords: Dentists in Al-Madinah, Musculoskeletal disorders, Prevalence.

How to cite this article: Al-Gunaid TH, Abdulhai R, Flemban B. Prevalence of Musculoskeletal Disorders among Dentists in Al-Madinah, Kingdom of Saudi Arabia. Int J Recent Surg Med Sci 2017;3(1):15-19.

\section{Source of support: Nil}

Conflict of interest: None

\footnotetext{
${ }^{1}$ Associate Professor, ${ }^{2,3}$ Student

${ }^{1-3}$ Department of Pediatric Dentistry and Orthodontics, College of Dentistry, Taibah University, Al-Madinah, Kingdom of Saudi Arabia

Corresponding Author: Talat H Al-Gunaid, Associate Professor, Department of Pediatric Dentistry and Orthodontics College of Dentistry, Taibah University, Al-Madinah, Kingdom of Saudi Arabia, Phone: +966505354055, e-mail: gunaid2000@ hotmail.com
}

\section{INTRODUCTION}

Among the health professionals, dentists are most likely to have high possibility of developing many professionassociated disorders, such as musculoskeletal disorders (MSDs). ${ }^{1}$ Dental professionals had an increased risk of developing such disorders caused by repetitive precision demanding handgrips, difficult work positions, large cervical flexion and rotation, extreme precise procedures, and long treatment time to spend in the patient's mouth. ${ }^{2,3}$ All of these factors may produce muscular pain, discomfort, less productivity, reduced work hours, and eventually will reduce benefits in terms of efficiency and reliability of dentists and their practices. ${ }^{4}$

Several studies have indicated that back, neck, and shoulder pain are major problems among dentists and have been revealed that special factors, such as gender, work duration, age, number of years working, and length of working time are possible causes of MSDs. ${ }^{5,6}$

The musculoskeletal health of dental professionals has been a subject of interests for numerous studies worldwide. ${ }^{7-17}$ Although several studies regarding prevalence of MSDs among dentists, as well as its predisposing factors have been published, only few studies have investigated the prevalence of MSDs among dentists in Kingdom of Saudi Arabia. ${ }^{10-12}$

Obtaining accurate information on the prevalence and impact of MSDs is meaningful, may help to identify specific risk factors, provide more comprehensive awareness of the underlying causes, and effective measures for reducing MSDs among dentists in Al-Madinah and elsewhere. Therefore, the aim of the study was to investigate the prevalence and distribution of musculoskeletal symptoms and to find the possible correlation between MSDs and different indicators, such as gender, experience, and length of working time.

\section{MATERIALS AND METHODS}

This study was approved by the ethical research committee at the Faculty of Dentistry, Taibah University, Kingdom of Saudi Arabia. A descriptive cross-sectional design was used to carry out this study. A questionnaire was distributed by hand to 180 dentists working in different public and private clinics in Al-Madinah city, Kingdom of Saudi Arabia. The questionnaire used in this study was adopted and modified from previous studies. ${ }^{11}$ In order to examine 
the validity of the study, we administered a questionnaire to the ethical committee for final approval and invited 30 assessors to participate in evaluating the questionnaire and give their feedback. The sample size was estimated after visiting different sectors of health-care providers in the city. The questionnaire involved information related to the location of symptoms in the past 12 months, last month, and last week. Additional information related to age, gender, height, weight, specialty, number of years of practice, number of working hours per week, number of working hours per day, and number of patients treated per day. The candidates were selected from governmental and private dental centers. Inclusion criteria were being a dentist, working in one of Al-Madinah institutes, acceptance to voluntarily participate in the study, whereas exclusion criteria were congenital MSDs, rheumatoid arthritis, previous surgeries, pregnancy, and refusing to participate for any reason. Data were anonymously coded and entered into a spreadsheet program before being analyzed. Appropriate statistical methods, such

Table 1: Background characteristics of the study population

\begin{tabular}{ll}
\hline Variable & Participants $(n=70)$ \\
\hline Sex (\%) & \\
$\quad$ Male & $47(67.1 \%)$ \\
Female & $23(32.9 \%)$ \\
Age (mean \pm SD) & $36.1 \pm 8.7$ \\
Specialty (\%) & $25(35 \pm 8 \%)$ \\
$\quad$ Surgery & $4(5.7 \%)$ \\
Peridontics & $4(5.7 \%)$ \\
Restorative & $4(5.7 \%)$ \\
Pedodontics & $2(2.9 \%)$ \\
Prosthodontics & $4(5.7 \%)$ \\
Orthodontics & $7(10 \%)$ \\
General practitioners & $45(64.2 \%)$ \\
Experience (years) (mean \pm SD) & $12 \pm 9.8$ \\
Working hours per week (mean \pm SD) & $32 \pm 17.5$ \\
Working hours per day (mean \pm SD) & $6.4 \pm 2.4$ \\
Patients per day (mean \pm SD) & $2.6 \pm 1.7$ \\
Rest breaks (minutes) (mean \pm SD) & $5.5 \pm 5.6$ \\
\hline
\end{tabular}

SD: Standard deviation as frequency, descriptive measures, chi-square test, and linear logistic regression test were performed in proper context. All statistical analyses were performed using Statistical Package for the Social Sciences version 17.0 (Chicago, Illinois, USA). The level of significance was set at $\mathrm{p}<0.05$.

\section{RESULTS}

Background characteristics of the study population are shown in Table 1. Among 70 dentists responded, 47 (67.1\%) were males and $23(32.9 \%)$ were females. The mean age was $36.1 \pm 8.7$ years. Majority [45 (64.2\%)] were general dental practitioners, and $25(35.8 \%)$ were specialists (surgery -4 ; periodontics -4 ; restorative -4 ; pedodontics - 2; prothodontics -4 ; and orthodontics -7 ). The mean working experience was $12 \pm 9.8$ years, and the mean working hours per week and per day were found to be $32 \pm 17.5$ and $6.4 \pm 2.4$ hours respectively. The mean number of patients treated per day was $2.6 \pm 1.7$, and the dentists take only $5.5 \pm 5.6$ minutes as rest beak between patients.

Table 2 exhibits the distribution of age groups by gender. Thirty-one of the sample $(44.3 \%)$ were in the middle age group, and only $7(10 \%)$ were older than 50 years.

The prevalence of MSDs by body site for the total sample and comparison between male and female groups are shown in Table 3. Most dentists reported having at least one MSD symptom in the past 12 months. The most prevalent musculoskeletal complaints during the previous 12 months were found at the lower back (65.7\%), neck

Table 2: Distribution of age groups by gender

\begin{tabular}{llll}
\hline & \multicolumn{3}{c}{ Gender } \\
\cline { 2 - 4 } Age group & Total $(\mathrm{n}=70)$ & Male $(\mathrm{n}=47)$ & Female $(\mathrm{n}=23)$ \\
\hline $20-29$ & $15(21.4 \%)$ & $9(19.1 \%)$ & $6(26.1 \%)$ \\
$30-39$ & $31(44.3 \%)$ & $22(46.8 \%)$ & $9(39.1 \%)$ \\
$40-49$ & $17(24.3 \%)$ & $11(23.4 \%)$ & $6(26.1 \%)$ \\
$\geq 50$ & $7(10 \%)$ & $5(10.6 \%)$ & $2(8.7 \%)$ \\
\hline
\end{tabular}

Table 3: Prevalence of musculoskeletal symptoms in the previous 12 months by location and gender

\begin{tabular}{|c|c|c|c|c|c|c|c|}
\hline \multirow[b]{2}{*}{ Pain location } & \multicolumn{2}{|c|}{ Total $(n=70)$} & \multicolumn{2}{|c|}{ Male $(n=47)$} & \multicolumn{2}{|c|}{ Female $(n=23)$} & \multirow[b]{2}{*}{$p$-value } \\
\hline & Yes (\%) & No (\%) & Yes (\%) & No (\%) & Yes (\%) & No (\%) & \\
\hline Neck & $34(48.6)$ & $36(51.4)$ & $24(51.1)$ & $23(48.9)$ & $10(43.5)$ & $13(56.5)$ & 0.51 \\
\hline Shoulders & $32(45.7)$ & $38(54.3)$ & $22(46.8)$ & $25(53.2)$ & $10(43.5)$ & $13(56.5)$ & 0.79 \\
\hline Upper back & $30(42.9)$ & $40(57.1)$ & $21(44.7)$ & $26(55.3)$ & 9 (39.1) & $14(60.9)$ & 0.65 \\
\hline Elbows & $14(20)$ & $56(80)$ & $8(17)$ & 39 (83) & $6(26.1)$ & $17(73.9)$ & 0.37 \\
\hline Wrist/hands & $25(35.7)$ & $45(64.3)$ & $16(34)$ & $31(66)$ & $9(39.1)$ & $14(60.9$ & 0.67 \\
\hline Lower back & $46(65.7)$ & $24(34.3)$ & $33(70.2)$ & $14(29.8)$ & 13 (56.5) & $10(43.5)$ & 0.25 \\
\hline Hips/thighs & $12(17.1)$ & $58(82.9)$ & $7(14.9)$ & $40(85.1)$ & $5(21.7)$ & $18(78.3)$ & 0.47 \\
\hline Knees & $20(28.6)$ & $50(71.4)$ & $13(27.3)$ & 34 (72.3) & $7(30.4)$ & $16(69.6)$ & 0.8 \\
\hline Ankles/feet & $14(20)$ & $56(80)$ & 7 (14.9) & $40(85.1)$ & 7 (30.4) & $16(69.6)$ & 0.12 \\
\hline
\end{tabular}
$\mathrm{p}<0.05$ 
$(48.6 \%)$, and shoulder $(45.7 \%)$, with the lowest prevalence found in the hips and thighs (17.1\%). No significant difference between male and female groups was found.

Table 4 shows the correlation between MSDs and different related factors, such as number of years of experience, number of patients, and working duration and length.

Significant correlation was found between neck pain and number of working hours per week $(\mathrm{r}=0.27 ; \mathrm{p}<0.05)$ and per day $(\mathrm{r}=0.30 ; \mathrm{p}<0.01)$.

Shoulder pain was significantly correlated with number of years of experience $(r=0.28 ; \mathrm{p}<0.01)$ and number of working hours per week $(\mathrm{r}=0.20 ; \mathrm{p}<0.05)$.

Upper back pain was significantly correlated with number of years of experience $(r=0.23 ; p<0.05)$, number of working hours per week $(r=0.29 ; p<0.01)$, number of working hours per day $(\mathrm{r}=0.34 ; \mathrm{p}<0.01)$, and number of patients per day $(\mathrm{r}=0.23 ; \mathrm{p}<0.05)$.

Elbows pain was significantly correlated with number of working hours per week $(r=0.23 ; p<0.05)$ and number of working hours per day $(\mathrm{r}=0.31 ; \mathrm{p}<0.01)$. Whereas lower back pain was significantly correlated only with number of years of experience $(r=0.22 ; p<0.05)$, hips and thighs pain were significantly correlated with number of working hours per week $(r=0.20 ; p<0.05)$.

\section{DISCUSSION}

The current study aimed to determine the prevalence of MSDs among dentists in working in Al-Madinah and to find possible correlation between the prevalence of MSDs and different risk factors.

The findings of this study showed that the frequency of pain and discomfort in the lower back, neck, and shoulders was relatively high. This finding is similar to those reported by Acharya et al, ${ }^{11}$ Abduljabbar, ${ }^{12}$ and Leggat and Smith. ${ }^{13}$

Lower back pain was the most common (65.7\%) followed by neck pain (48.6\%) and shoulder pain (45.7\%). However, in the last 12 months the prevalence of lower back pain $(65.7 \%)$ was found to be similar to that reported for Taiwanese $(66.5)^{18}$ and higher than that reported by Acharya et $\mathrm{al}^{11}(52.4 \%)$ for Nepalese, Abduljabbar ${ }^{12}$ $(52.1 \%)$ for Saudis in Riyadh, and Leggat and Smith ${ }^{13}$ (53.7) for Australians.

The prevalence of neck pain was the second most commonly reported pain among dentists in Al-Madinah $(48.6 \%)$. This is less than that reported by Acharya et $\mathrm{al}^{11}(52.4 \%)$ in Nepal, Al Wazzan et $\mathrm{al}^{10}(65 \%)$ and Abduljabbar $^{12}$ (67.9\%) for Saudis, Leggat and Smith ${ }^{13}$ (57.5\%) for Australians, and Lin et $\mathrm{al}^{18}$ (66.5\%) for Taiwanese, but higher than that reported by Ratzon et al ${ }^{17}$ (38.3\%) for Israelis.

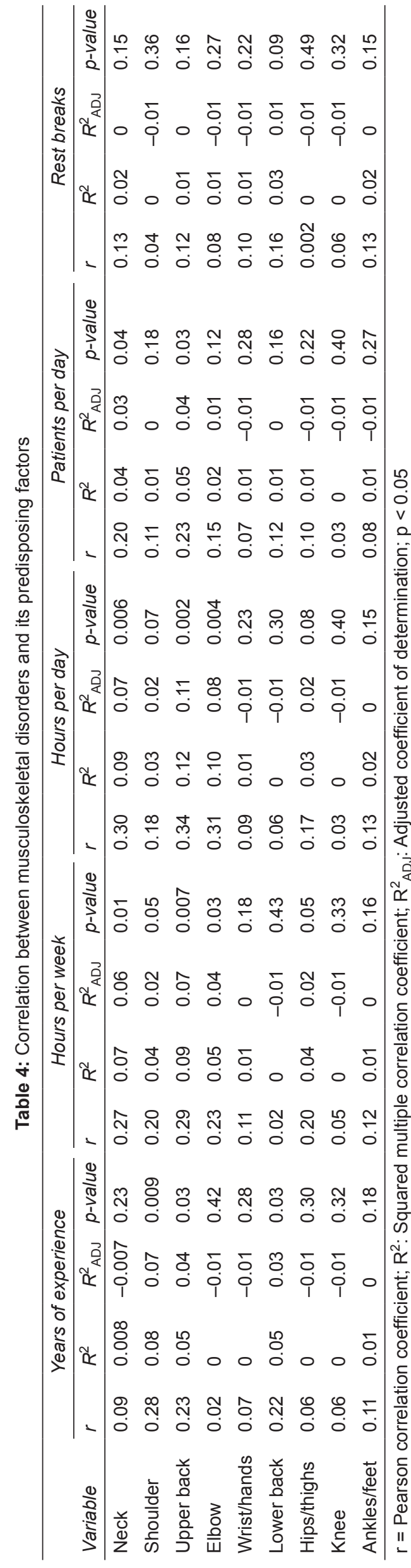


The prevalence of shoulder pain was found to be $45.7 \%$. This is similar to those reported by Acharya et al ${ }^{11}$ $(49.5 \%){ }_{1}^{11}$ and less than those observed by Leggat and Smith $^{13}(53.3 \%)$, and Lin et al ${ }^{18}(75.1 \%)$ for Taiwanese.

In the present study, no statistically significant differences were found in the incidence of MSDs between male and female groups. This is in contrast to that reported by Abduljabbar ${ }^{12}$ who found higher significant difference between male and female groups and concluded that could be attributed to the lower threshold of tolerance of female compared with male, a trend that has not been observed in our study.

The finding of this study showed significant correlation between shoulder pain, upper back pain, and lower back pain with the years of experience. In this regard, it was reported that less experienced dentists are more likely to suffer from musculoskeletal pain than their more experienced counterparts. ${ }^{18}$ The possible explanations were that experienced dentists are probably better at adjusting their working position and techniques in order to avoid musculoskeletal problems compared with their less experienced counterparts, or they simply developed coping strategies to deal with the pain. ${ }^{18}$

The results of this study showed a significant correlation between neck, shoulder, upper back, and elbow pain with the number working hours per week and per day.

In this investigation, all respondents work in an irrational situation for an average of $6.4 \pm 2.4$ hours a day and $32 \pm 17.5$ hours per week, causing overloading of the musculoskeletal system for a comparatively long time. This corresponds with the report of Lin et $\mathrm{al}_{1}^{18}$ in that maintaining this kind of poor posture during dental treatment for an extended period of time might cause discomfort to the entire body.

In addition, Marshall et $\mathrm{al}^{15}$ suggested a 10-minute break during the treatment; therefore, insufficient rest breaks (5.5 \pm 5.6 minutes) for dentists practicing in Al-Madinah could be a reason.

Al Wazzan et a ${ }^{10}$ reported that the increase in weekly working hours resulted in the increase in the prevalence of back pain and had little effect on the neck pain, and that could be attributed to the practicing of back postural faults more than neck postural faults.

The finding of the present study may raise attention to the importance of initiation and implantation of special courses or workshops about MSDs and its predisposing factors. Continuing education for dentists and dental students about the proper and correct dental positions as well as practicing ergonomic skills to avoid MSDs would be beneficial, and that should be a part of the curriculum for the dental students.

Finally, the limitations of this study must be acknowledged as including a relatively small number of subjects due to the leak of dentists' cooperation. Moreover, most of the dentists either in governmental or in private institutes reported that they do not have time to conduct the questionnaires, even though the questionnaire was designed to be filled within 5 minutes only. In spite of these limitations, some obvious trends toward the prevalence of MSDs among each group and its aggravating factors included in this study are possibly helpful. Further studies including larger number of subjects from different parts of the kingdom are recommended.

\section{CONCLUSION}

- The results suggested that the prevalence of musculoskeletal symptoms among dentists in Al-Madinah is high.

- Lower back pain is the most common complaint followed by neck pain and shoulder pain.

- Continuing education for dentists and dental students about the proper and correct dental positions as well as practicing ergonomic skills and incorporating it in the curriculum would be beneficial.

\section{REFERENCES}

1. Puriene A, Aleksejuniene J, Petrauskiene J, Balciuniene I, Janulyte V. Self-reported occupational health issues among Lithuanian dentists. Ind Health 2008 Aug;46(4):369-374.

2. Akesson I, Johnsson B, Rylander L, Moritz U, Skerfving S. Musculoskeletal disorders among female dental personnel - clinical examination and a 5-year follow-up study of symptoms. Int Arch Occup Environ Health 1999 Sep;72(6):395-403.

3. Rundcrantz BL, Johnsson B, Moritz U. Pain and discomfort in the musculoskeletal system among dentists. A prospective study. Swed Dent J 1991 Feb;15(5):219-228.

4. Shugars DA, Williams D, Cline SJ, Fishburne C Jr. Musculoskeletal back pain among dentists. Gen Dent 1984 Nov-Dec;32(6):481-485.

5. Rundcrantz BL, Johnsson B, Moritz U. Cervical pain and discomfort among dentists. Epidemiological, clinical and therapeutic aspects. Part 1. A survey of pain and discomfort. Swed Dent J 1990 Feb;14(2):71-80.

6. Valachi B, Valachi K. Preventing musculoskeletal disorders in clinical dentistry: strategies to address the mechanisms leading to musculoskeletal disorders. J Am Dent Assoc 2003 Dec;134(12):1604-1612.

7. Akesson I, Schutz A, Horstmann V, Skerfving S, Moritz U. Musculoskeletal symptoms among dental personnel; lack of association with mercury and selenium status, overweight and smoking. Swed Dent J 2000 Feb;24(1-2):23-38.

8. Murtomaa H, Haavio-Mannila E, Kandolin I. Burnout and its causes in Finnish dentists. Community Dent Oral Epidemiol 1990 Aug;18(4):208-212.

9. Ylipaa V, Arnetz BB, Preber H. Factors that affect health and well-being in dental hygienists; a comparison of Swedish dental practices. J Dent Hyg 1999 Fall; 73(4):191-199.

10. Al Wazzan KA, Almas K, Al Shethri SE, Al-Qahtani MQ. Back and neck problems among dentists and dental auxiliaries. J Contemp Dent Pract 2001 Aug;2(3):17-30. 
11. Acharya RS, Acharya S, Pradhan A, Oraibi S. Musculoskeletal disorders among dentists in Nepal. Journal of Nepal Dental Association 2010 Jul-Dec;11(2):107-113.

12. Abduljabbar TA. Musculoskeletal disorders among dentists in Saudi Arabia. Pak Oral Dent J 2008;28(1):135-144.

13. Leggat PA, Smith DR. Musculoskeletal disorders self-reported by dentistsin Queensland, Australia. AustDentJ2006 Dec;51(4): 324-327.

14. Rising DW, Bennett BC, Hursh K, Plesh O. Reports of body pain in a dental student population. J Am Dent Assoc 2005 Jan;136(1):81-86.
15. Marshall ED, Duncombe LM, Robinson RQ, Kilbreath SL. Musculoskeletal symptoms in New South Wales dentists. Aust Dent J 1997 Aug;42(4):240-246.

16. Oberg T, Oberg U. Musculoskeletal complaints in dental hygiene: a survey study from a Swedish county. J Dent Hyg 1993 Jul-Aug;67(5):257-261.

17. Ratzon NZ, Yaros T, Mizlik A, Kanner T. Musculoskeletal symptoms among dentists in relation to work posture. Work 2000 Feb;15(3):153-158.

18. Lin TH, Liu YC, Hsieh TY, Hsiao FY, Lai YC, Chang CS. Prevalence of and risk factors for musculoskeletal complaints among Taiwanese dentists. J Dent Sci 2012 Mar;7(1):65-71. 